\title{
Reflection on Crucial Issues in Enterprise Operation Management
}

\author{
Jiangai Xue \\ School of economics and management, Nanyang Institute of Technology, Nanyang, Henan, 473000, \\ China
}

Keywords: Wastewater treatment, Enterprise, Operation management

\begin{abstract}
Water is the source of life, and in case of water pollution, people's production and life is bound to be greatly affected. Among them, deficiencies in the operation and management of wastewater treatment enterprises, can easily lead to substandard wastewater treatment, thereby affecting the overall local water quality. This paper discusses the urgency to strengthen the wastewater treatment plant operation and management, analyzes the crucial issues of the current wastewater treatment plant operation and management and proposes measures to solve crucial problems of wastewater treatment plant operation and management.
\end{abstract}

\section{Introduction}

Currently, acceleration of the urbanization process in China causes great pressure on the environment; especially water pollution problem has greatly affected the daily lives of the residents, which produces the big threat for physical and mental health of the moderns. Visibly, water pollution situation has developed to the extent that it must be solved. Meanwhile, with the continuous progress of China's modernization and industrialization, the total amount of wastewater discharge increases constantly. From 2001 to 2012, the total amount of wastewater discharge increased from 43.3 billion tons (in 2001) to 68.5 billion tons (in 2012). The total amount of wastewater discharge increased 25.2 billion tons, the average annual discharge increased 2.1 billion tons of wastewater, and the average annual compound growth rate is about 4.3\%. Accordingly, in order to effectively resolve existing water pollution problems, we must strengthen the operation and management of wastewater treatment enterprises, so as to provide a solid guarantee for the health of urban residents.

\section{The urgency to strengthen operation management of wastewater plants in China}

First, to strengthen the operation management of the wastewater plants in China is the requirement to strengthen the environmental protection under the new situation. It is expressly put forward in China's "Twelfth Five-Year Plan" that we should perfect unified, open and orderly modern new operation and management mechanism, which requires wastewater treatment enterprises to use more productive initiatives to implement operational management. The joint efforts of relevant parties can truly promote China's environmental protection cause to make new progress. Second, to strengthen the operation management of the wastewater plants in China is the requirement to promote environmental protection cause to achieve new development. Today, there exists a considerable gap between realities of China's wastewater treatment enterprise and market demands, showing that the wastewater treatment plant operation has a very large market potential for development. In order to effectively transforming this market potential, the key is to effectively change the current management system, and promote the diversification of business investment through the implementation of more active investment and financing instruments. Third, to strengthen the operation management of the wastewater plants in China is the requirement to improve the degree of public participation. It can be said that wastewater treatment is the public welfare directly related to the interests of members of the whole society. Therefore, wastewater treatment enterprises must increase emphasis on operational management, enhance participation by the majority of the public, and then create a better investment condition for all types of investors to actively participate in the community. 


\section{Crucial issues in operation management of current wastewater treatment plants}

First, management mechanism has deficiencies, and supporting facilities are inadequate. Today, in China many wastewater treatment enterprises are strongly dependent on the financial allocation for investment construction, therefore, there exist a number of problems in the construction and renovation, and the investment subject is extremely single. This management approach will lead to a lack of adequate competition between wastewater treatment enterprises, resulting in that there is a large number of staff but the efficiency is very low. With strong fiscal dependence but failed to establish a good financial monitoring mechanism, naturally there will be tremendous waste of money, and this is also resulted from imperfect operation management system. At the same time, inadequate supporting equipment and facilities of many wastewater treatment enterprises result in poor urban wastewater treatment. Some local wastewater treatment enterprises enhance the intensity of infrastructure construction, but it is unreasonable in terms of the particular disposal methods, therefore, it is difficult to play the active role of wastewater treatment enterprises. A large number of wastewater treatment enterprises have not yet established wastewater treatment emergency mechanism, and they cannot implement quick and efficient treatment in case of accidents, which thus has a negative impact on the safe operation of wastewater enterprises.

Second, the technology of a considerable number of wastewater treatment enterprises is lagged, and they lack professional and technical personnel. Production of our wastewater treatment equipment began in the late seventies of last century, but these products did not have high level of standardization, complete set and serialization. After the seventies, wastewater treatment equipment research and development capability has made substantial progress. Now, wastewater treatment plants with daily treatment of 5,10,25,50 tons can achieve localization of major equipment, among which, domestic microporous aeration, high-strength aerators, belt filter press, various grid decontamination machines, scraping mud machine, scraping sand machine, aeration brush, aeration blowers, large wastewater pumps, and submersible pumps have been basically able to meet the domestic market demand, and there are some products for export. But for the larger energy blowers, pumps and other products, stand-alone device efficiency is close to the international level in the nineties. Technology related with biogas power generation, on-line monitoring and other aspects, compared with Western countries, has a considerable gap due to the constraints of technical problems, resulting in low wastewater treatment efficiency and the degree of automation, thus greatly affecting improvement of the overall capacity of our wastewater treatment. In terms of the technical level, we lack professional personnel, and overall skill level of wastewater treatment workers is not high enough, and a few cannot even meet the national minimum requirements for practitioners in waste water industry. Obviously, the overall quality, particularly the professional quality, of our wastewater treatment practitioners urgently needs to be enhanced.

Third, there exists a significant tendency to focus on the construction but neglect operation. For the overall development of our society, there are so many reasons for difficulty development of the wastewater treatment enterprises. One of very important reasons is the inadequate emphasis on operation management. Wastewater treatment enterprises can get funds through various channels during their construction, so they rarely consider the various costs that may arise in the future operation management during the planning and design stage, but will for the pursuit of performance, generally adopt too large and unprecedented scale, and one-sidedly pursue the so-called global leader, which results in extremely expensive costs in the operation and maintenance of wastewater treatment plants, so, it can be said that a considerable portion of our wastewater treatment enterprises seem flashy but impractical, without enough capacity to deal with large amount of wastewater.

\section{Measures to resolve crucial issues of operation management of wastewater treatment plants}

Change concept and form new concept of wastewater treatment. Due to continuously strengthened urbanization trends, overall water resources in China tend to become increasingly strained. Usually, there will be a very deep impression in people' s minds that all wastewater is waste. This requires proper understanding of the concept of wastewater treatment, and modern people 
must have new wastewater treatment concept, which is to fully understand the important value of wastewater treatment in optimizing urban environment, protecting physical and mental health of the local people and other aspects. This requires to strengthen publicity and education, so that the general public can strengthen the protection of water resources based on water resources protection and utilization law, and thus to better enhance the utilization water resource has.

Develop capital input to perfect wastewater treatment supporting facilities. Wastewater treatment enterprises have quite high requirements for capital, because wastewater treatment enterprises themselves are difficult to get profit and therefore once the funds cannot be timely obtained, the reasonable operation of wastewater treatment enterprises are bound to be affected. Therefore, wastewater treatment enterprises should strengthen supervision of financial capital invested by the country, thus truly ensure better enterprise operation without wasting financial resources. In terms of the technical level, enterprises should aim to increase investment in science and technology, continue to enhance independent innovation ability of technology in the field of wastewater treatment. Only truly equipped with the key technology of wastewater treatment, we can better guarantee the quality of wastewater treatment.

Promote operation management of wastewater treatment enterprises. First, we must improve the environment of wastewater treatment enterprise production plant, strengthen the training and education of employees, perfect health management system of production plant to ensure production plant can be always kept clean. Once problem arises in the work, should quickly rectify personnel responsible for management, so as to prevent adverse situations such as delay and prevarication, etc., and form positive work environment. Production markings should be labeled in the obvious place and personnel engaged in the operation should have a better understanding of specific work situation. On this basis, pre-service training should be conducted for specific operators in production plant of the wastewater treatment enterprises, to ensure that they all can have professional qualification certificates of wastewater treatment workers, but also pre-service testing needs to be perform and only qualified workers are permitted for operation. Also strengthen the education and training of employees in specific work process and enhance their professional skills and sense of responsibility.Second, focus on on-site internship of new workers of wastewater treatment enterprises, and also implement comprehensive simulation exercises of abnormal situations for on-duty staff. For those newly employees passing the practical and theoretical training and examination, we should practically and reasonably arrange them to carry out site work in the production plant, and let them really grasp the characteristics of wastewater treatment system of enterprises as well as specific methods of operation from practice. On this basis, we should also actively enhance practical skills of employees. Of course, for on-duty staff of the wastewater treatment enterprises, we should also regularly or irregularly implement simulation training of all types of possible anomalies, so that specific operators can improve their ability to handle all types of different situations.Third, form commonly-used wastewater treatment system operating instruction specification. Wastewater treatment enterprises should divide and various professions prepare specific operation instruction specification manual for the system based on the actual situation, and organize training of employees on this manual. Based on specific conditions in production plant of wastewater treatment enterprises, regularly update and improve this manual, so that employees can really get scientific and standardized guidance on their operation.

Fully consider actual situation and lower wastewater treatment effluent standard. Formulation of wastewater treatment effluent standard must seriously and practically consider China's specific national conditions, for example, economic strength some regions is still not strong, and there exists a considerable distance between the effluent standard after wastewater treatment in China and in Western countries. This is because due to the gradual increase of economic strength, effluent standard of wastewater treatment enterprises in Western countries is also rising. For example, the membrane was adopted by the United States in the 1970s, and the high-load biofilter has been promoted to more than $70 \%$ of wastewater treatment enterprises. And this is only because the technique needs less energy, runs more stably and costs less. Thereafter, in view of the gradual increase of American economic strength, the original biofilter technology has been unable to meet the 
increasingly high effluent standards, and they began using active sludge method and other new technologies. In view of this, during specific research and development process of the relevant technology and facilities, China's national conditions in the current stage must be fully taken into account on the reasonable basis.

Enhance supervision work and effectively supervise wastewater treatment plant operation management. Investment and use of wastewater treatment enterprises mean that China's wastewater treatment career began to tend to be sound and perfect. In order to ensure the reasonable implementation of wastewater treatment, be sure to use the regulatory approach with full execution, and supervise operation conditions of all aspects of wastewater treatment enterprises. At the same time, for the internal management of wastewater treatment enterprises, strictly control water quality discharged after wastewater treatment, to make sure the discharged wastewater can meet current related wastewater treatment quality and safety standards in China. Local governments should also constantly enhance the intensity of supervision, and for those wastewater treatment enterprises that do not meet the standard, order them to improve; for those with serious circumstances, make them banned, thus promoting China's wastewater treatment enterprises to operate smoothly. Because a lot of security problems tend to occur during operation of wastewater treatment enterprises, which requires to constantly strengthen the internal organization construction, effectively enhance the sense of crisis for operation management of wastewater treatment enterprise. In order to be able to honestly ensure the quality of enterprise operation management, and effectively reduce the incidence of various types of security incidents, we must genuinely strengthen the oversight, and more strictly control quality of wastewater treatment enterprises. Of course, during this process we also should improve and perfect various emergency measures during wastewater treatment process. Once security incident occurs, apply reasonable approach to make it addressed to ensure long-term safe operation of wastewater treatment enterprises.

Perfect internal system supporting project construction of wastewater treatment enterprises. Based on the principles of "enterprise network supporting and management network first" , constantly improve the intensity and strength of treatment load of wastewater treatment enterprises. Constantly increase investment in local rainwater and wastewater diversion project, truly realize comprehensive diversion between wastewater and rainwater, and make sure better operation of wastewater treatment enterprises. At the same time, also improve sludge disposal facilities for more secure and centralized sludge treatment, and be committed to enhancing the recycling rate of water. To this end, we should actively explore water resources pricing system, make specific policies and supporting initiatives practicable, and comprehensively promote the recycling economy to achieve new development.

\section{Conclusions}

In summary, wastewater treatment is an extremely complicated systematic project. We must be tireless to implement for a long term, and then we can see the effectiveness. For wastewater treatment plants, the main objective of its operation management is not only to ensure smooth operation of enterprises, and discharge standardized water after treatment through the implementation of safer production, but also achieve the most reasonable operation management by the lowest cost. At the same time, be committed to expanding the scope of work of wastewater treatment enterprises, thus try to realize the value maximization of the use of wastewater treatment facilities, and then obtain better operational efficiency.

\section{References}

[1] Liu Pingyang, Li Hui, Liu Jia. On market-oriented pattern of operation management of China's small urban wastewater treatment plants. Productivity Research, 2010 (1).

[2] Li Yingying. Analysis on situation and countermeasures of wastewater treatment in China. Oriental Enterprise Culture, 2011 (2). 
[3] Li Weilin. How to optimize wastewater treatment plant operation management. Beijing Environment, 2011 (4).

[4] Li Heyi. Reflection on market-oriented operation of urban wastewater treatment plants. Resources and Resident Environment, 2011 (8).

[5] Lin Zuosheng, Wang Yanrui. Problems and countermeasures of urban wastewater treatment. Science Communication, 2011 (10).

[6] Ou Daqian. Problems and countermeasures of urban wastewater treatment. Science and Technology for Development (application version), 2012 (2). 